\title{
miR-335-5p Inhibits Progression of Uterine Leiomyoma by Targeting ARGLU1
}

\author{
Wei Zhao $\mathbb{D}^{1},{ }^{1}$ Yingyan Zhao $\mathbb{D},{ }^{2}$ Ling Chen $\mathbb{D}^{2},{ }^{2}$ Yan Sun $\mathbb{D}^{2},{ }^{2}$ and Sumei Fan $\mathbb{D}^{3}$ \\ ${ }^{1}$ Department of Clinical Laboratory, Women's Hospital of Nanjing Medical University, Nanjing Maternity and Child Health \\ Care Hospital, 123 Tianfei Lane, Mochou Road, Nanjing, Jiangsu 210004, China \\ ${ }^{2}$ Department of Obstetrics and Gynecology, Zhangjiagang Hospital of Traditional Chinese Medicine \& Affiliated Zhangjiagang \\ Hospital of Nanjing University of Chinese Medicine, Zhangiiagang 215600, China \\ ${ }^{3}$ Department of Geriatrics, The Affiliated Huai'an Hospital of Xuzhou Medical University and the Second People's Hospital \\ of Huai'an, No. 62, Huaihai Road (S.), Huaian, Jiangsu 223002, China
}

Correspondence should be addressed to Yan Sun; yan_sun1981@126.com and Sumei Fan; huaianfansumei@126.com

Received 25 July 2021; Accepted 9 November 2021; Published 17 January 2022

Academic Editor: Chang Gu

Copyright (c) 2022 Wei Zhao et al. This is an open access article distributed under the Creative Commons Attribution License, which permits unrestricted use, distribution, and reproduction in any medium, provided the original work is properly cited.

\begin{abstract}
Studies have demonstrated that miR-335-5p exhibits an essential role in the progress of multiple tumors, including thyroid cancer, pancreatic cancer, and non-small-cell lung cancer. However, the possible expression, the detailed role, and the underlying mechanisms of miR-335-5p in uterine leiomyoma (UL) still remained unclear. Therefore, the present study was designed to investigate the mechanism and function of miR-335-5p in UL. In our study, microRNA-335-5p (miR-335-5p) is significantly downregulated in UL tissues and UL cell lines, especially in HCC1688 and SK-UT-1 cells. Functionally, overexpression of miR335-5p notably inhibits the viability of UL cell lines by CCK-8 assay. Besides, upregulation of miR-335-5p inhibits proliferation of UL cell lines by colony formation assay and decreases the protein levels of PCNA and Ki-67 detected by western blot assay. In addition, overexpression of miR-335-5p induces UL cell cycle arrest at G1 phase. Upregulation of miR-335-5p decreases the levels of Cyclin A1, Cyclin B1, and Cyclin D2 and upregulates the expression of p27 protein. Additionally, upregulation of miR-335-5p promotes the apoptosis of UL cell lines, increases the protein levels of Bax, Cleaved caspase-3, and Cleaved caspase-9, and decreases the protein expression of Bcl-2. Moreover, Arginine and Glutamate-Rich protein 1 (ARGLU1) is predicted as a target of miR-335-5p by ENCORI and miRDB and confirmed by dual-luciferase reporter assay. ARGLU1 is negatively associated with miR-335-5p. Furthermore, overexpression of ARGLU1 partly restores the effects of miR-335-5p mimic on the viability, proliferation, cell cycle, and apoptosis of UL cell lines. To conclude, miR-335-5p may play a repressive role in UL by targeting ARGLU1 and serve as a potential therapeutic target for the treatment of UL.
\end{abstract}

\section{Introduction}

Uterine leiomyoma (UL) is the most common benign tumor in women of childbearing age [1]. UL, also known as uterine fibroids, are monoclonal tumors of the smooth muscle tissue layer (myometrium) of the uterus. It is reported that $70 \%$ $80 \%$ of women will suffer from UL in their lifetime and about $20 \%$ of them need clinical treatment such as hysterectomy [2]. Therefore, UL is a common disease, seriously endangering women's physical and mental health. However, in view of such a high incidence rate, we know little about the etiology and pathogenesis of UL. In recent years, genetic epidemiological studies have found that the occurrence of UL tends to be familial aggregation, and the risk of UL is increasing in women who have not given birth [3]. Flake et al. finds that nearly $40 \%$ of UL has simple and nonrandom chromosomal abnormalities [4]. But so far, such a high incidence rate can be explained by genetic mechanisms that had not been recognized by academics and the lack of targeted gene therapy of UL.

MicroRNA (miRNA) is a newly discovered small molecule RNA (18-25 nt) [5]. At present, there are 1572 miRNAs identified in human genome, and about one third of human genes are regulated by miRNAs [6]. A miRNA can regulate 
multiple genes, and a gene can also be regulated by multiple miRNAs, thus forming a complex regulatory network and hierarchy in cells [7]. miRNAs play an important role in cell differentiation, apoptosis, and malignant transformation [8]. The current research confirms that miRNAs are expected to become important molecular markers for disease prediction and diagnosis and new tools and targets for disease treatment [9]. At present, a lot of research results have been achieved in the fields of malignant tumors, cardiovascular diseases, neuromuscular tissues, and stem cells [10-12]. However, the research on the expression of miRNAs in normal uterine smooth muscle and UL, the relationship between miRNAs, and occurrence and development of UL have just begun. For example, miR-93 is lowly expressed in UL tissues. Upregulation of miR-93 significantly reduces the cell viability, promotes cell cycle arrest, causes apoptosis, and inhibits migration of UL cells, accomplished by targeting CCND1 [13]. Besides, the expression of miR-139-5p in UL tissues is significantly lower. Overexpression of miR139-5p inhibits the growth and induces apoptosis and G1 phase arrest of UL cells through downregulating TPD52 [14].

As a member of miR-335 family, miR-335-5p is located in the intron region at chromosome position $7 \mathrm{q} 32.2$, which is widely expressed in many tissues [15]. Studies have demonstrated that miR-335-5p exhibits an essential role in the progress of multiple tumors, including thyroid cancer, pancreatic cancer, and non-small-cell lung cancer [16-18].

However, the possible expression, the detailed role and the underlying mechanisms of miR-335-5p in UL still remained unclear. Therefore, the present study was designed. As expected, miR-335-5p was downregulated in UL tissues and cell lines. Upregulation of miR-335-5p notably inhibited viability and proliferation, promoted apoptosis, and induced cell cycle arrest at the G1 phase of UL cells, which might be achieved by targeting Arginine and Glutamate-Rich protein 1 (ARGLU1), previously known as FLJ10154, and was a gene with poorly defined cellular function(s). Our findings implied that miR-335-5p functioned as a tumor suppressor and might serve as a new biomarker for therapeutic target for UL.

\section{Materials and Methods}

2.1. Specimen Collection. A total of 20 UL tissues and 20 corresponding adjacent tissues were collected from patients who were treated in the Zhangjiagang hospital and frozen at $-80^{\circ} \mathrm{C}$. All patients (24-48 years old) had no medical and surgery complications and menstruated normally. Moreover, no hormone treatment was taken within 3 months prior to operation, and all patients were confirmed UL by postoperative pathology. All patients had signed the written informed consents, and our experiments were approved by the Ethics Committee.

2.2. Cell Culture and Transfection. Uterine smooth muscle cell PHM1-31 and UL cell lines including HCC1688, HTMMT, SK-UT-1, and SKN were purchased from BioVector NTCC Inc. (Beijing, China). All the cell lines were cul- tured in Dulbecco's Modified Eagle Medium (DMEM, Invitrogen, Carlsbad, CA, USA) with 10\% fetal bovine serum (FBS, Invitrogen, Grand Island, NY, USA) and $1 \%$ penicillin-streptomycin (Sigma-Aldrich, St. Louis, MO, USA) under a $37^{\circ} \mathrm{C}$ humidified incubator with $5 \% \mathrm{CO}_{2}$.

For cell transfection, miR-335-5p mimic/inhibitor, pcDNA3.1 cloned with ARGLU1, and empty vectors were synthesized in Gene Pharma Company (Shanghai, China). UL cell lines $\left(3 \times 10^{5}\right)$ were maintained in 6-well plates and transfected with miR-335-5p mimic/inhibitor ( $50 \mathrm{nM})$ and/ or pc-ARGLU1 (50 ng) using Lipofectamine 2000 (Invitrogen, Carlsbad, CA, USA). After $48 \mathrm{~h}$, transfection efficiency was determined by qRT-PCR assay.

2.3. CCK-8 Assay. The cell proliferation of difference groups was measured by CCK- 8 assay. HCC1688 and SK-UT-1cells evenly in 96 well plates $\left(1 \times 10^{4}\right.$ cells per well). Then, cells were transfected and incubated for indicated times $(0,24$, 48 , and $72 \mathrm{~h}$ ), respectively. Cell viability was examined by CCK-8 kit (Beyotime Biotechnology, Shanghai, China) based on the specification. The optical density was detected at $490 \mathrm{~nm}$ by a microplate reader.

2.4. Colony Formation Assay. Colony formation assay was performed to evaluate the proliferative potential of UL cell lines after transfection. In brief, HCC1688 and SK-UT1cells at a density of $1 \times 10^{3} /$ well were seeded in 6-well plates, and the medium was replaced with fresh culture medium every 2-3 days for a total of $14 \mathrm{~d}$. Then, HCC1688 and SK-UT-1cells were stained using $10 \%$ crystal violet for $30 \mathrm{~min}$.

2.5. EdU Assay. EdU assay was carried out to evaluate the proliferation of UL cell lines after transfection. Briefly, HCC1688 and SK-UT-1 cells $\left(5 \times 10^{4}\right.$ per well) were cultured in 24-well plates and transfected for $48 \mathrm{~h}$. Then, cells were fixed with $4 \%$ paraformaldehyde, and Triton X-100 was used to permeabilize the nuclear membrane. Finally, cells were blocked with goat serum for $1 \mathrm{~h}$ and stained according to the manufacturer's instructions.

2.6. Cell Apoptosis Assay and Flow Cytometry Analysis. The apoptosis rate and cell cycle distribution of the transfected cells were detected by flow cytometry analysis. For cell apoptosis, HCC1688 and SK-UT-1 cells were inoculated with 2 $\times 10^{5}$ per well, and the cells and culture medium were collected at $48 \mathrm{~h}$ after transfection. Washing by PBS, $500 \mu \mathrm{L}$ binding buffer was added to the suspension cell and then mixed with $5 \mu \mathrm{L}$ Annexin V-FITC and $10 \mu \mathrm{L}$ PI. After $10 \mathrm{~min}$, the rate of apoptosis was detected by flow cytometry. For cell cycle, $1 \times 10^{6}$ HCC1688 and SK-UT- 1 cells from different groups were collected. Then, the cells were fixed by $70 \% \mathrm{EtOH}$ overnight and stained by PI for $30 \mathrm{~min}$. Finally, the distribution of cell cycle was detected by flow cytometry.

2.7. $q R T-P C R$ Assay. Total RNA was separated from UL cell lines by Trizol Reagent (Invitrogen, USA), cDNA was synthesized by TaqMan Reverse Transcription Kit (Applied Biosystems, USA). Routine RT-qPCR was implemented using ABI 7300-fast RT PCR system (Applied Biosystems, 
USA) with SYBR Green PCR Kit (Qiagen, Germany) based on the specifications. Relative expressions of miRNA and mRNA were evaluated by the $2^{-\Delta \Delta C t}$ method with U6 and $\beta$-actin as internal references. The primer sequences used were listed as follows: miR-335-5p-forward $5^{\prime}$-TCAAGA GCAATAACGAAAAATGT- $3^{\prime}$ and reverse $5^{\prime}$-TGCGGG TGCTCGCTTCGGC AGC-3'; U6-forward $5^{\prime}$-CTCGCT TCGGCAGCACATA- $3^{\prime}$ and reverse $5^{\prime}$-AACGCTTCACG AATTTGCGT-3'; ARGLU1-forward $5^{\prime}$-GAGCAGCAG AGAAAGGGA GA- $3^{\prime}$ and reverse $5^{\prime}$-CAGCCGAGCAC TCTAGCTCT- $3^{\prime}$; and $\beta$-actin-forward $5^{\prime}$-CACGAGTAC AACCT TC-3' and reverse $5^{\prime}$-CCCATACCCACCATCA CACC- $3^{\prime}$. Conditions for qRT-PCR were used: $95^{\circ} \mathrm{C}$ for $10 \mathrm{~min}, 40 \mathrm{cycles}$ of $95^{\circ} \mathrm{C}$ for $15 \mathrm{~s}$, and $60^{\circ} \mathrm{C}$ for $1 \mathrm{~min}$.

2.8. Western Blot. Protein from UL cell lines was isolated by RIPA lysis buffer and quantified by BCA kit (Beyotime Biotechnology). Protein was extracted by $12 \%$ SDS-PAGE and then shifted into PVDF membranes (Millipore, MA, USA). Next, the membranes were interfered with $5 \%$ nonfat milk and treated with the primary antibodies overnight at $4^{\circ} \mathrm{C}$. Then, membranes were washed and incubated with HRPconjugated secondary antibody $(1: 2,000$, ab6728) for $1 \mathrm{~h}$ at room temperature. At last, protein blots were observed by enhanced chemiluminescence kit (ECL, Millipore, Bedford, MA, USA) and quantified using ImageJ software (NIH, version 4.3). The primary antibodies were as follows: antiPCNA (1:1, 000, ab92552), anti-Ki-67 (1:1, 000, ab16667), anti-Cyclin A1 (1:1,000, ab53699), anti-Cyclin B1 (1:1, 000, ab32053), anti-Cyclin D2 (1:1,000, ab230883), antip27 (1:1, 000, ab62364), anti-Bax (1:1, 000, ab32503), anti-Bcl-2 (1:1, 000, ab32124), anti-Cleaved caspase-3 (1:1, 000, ab32042), anti-Cleaved caspase-9 (1:1, 000, ab2324), and anti- $\beta$-actin $(1: 2,000$, ab8227). All antibodies were obtained from Abcam (MA, USA).

2.9. Dual-Luciferase Reporter Assay. The $80 \mathrm{ng}$ wild-type and mutant ARGLU1 3'-UTR dual-Luciferase reporter vectors were constructed by subcloning the human ARGLU1 mRNA $3^{\prime}$-UTR and mutant $3^{\prime}$-UTR sequences into the dual-luciferase reporter vectors plasmids (Promega, Madison, USA). Cells were transfected with $80 \mathrm{ng}$ luciferase reporter vectors and $\mathrm{miR}-335-5 \mathrm{p}$ mimic using the Lipofectamine 2000. After $24 \mathrm{~h}$ incubation, dual-luciferase activities were measured.

2.10. Statistical Analysis. Data analysis was implemented by GraphPad Prism 5.0 and presented as the mean \pm standard deviation (SD). ANOVA followed by Tukey's post hoc analysis was employed to analyze the differences between groups. $P<0.05$ was indicated to be significant.

\section{Results}

3.1. miR-335-5p Is Downregulated in UL Tissues and Cell Lines. To assess the expression of miR-335-5p in UL tissues and cell lines, firstly, a total of $20 \mu \mathrm{L}$ clinical tissues were collected. As shown in Figure 1(a), miR-335-5p was obviously downregulated in UL tissues when compared with corresponding adjacent tissues. Moreover, qRT-PCR analysis was used to evaluate the expression of miR-335-5p in UL cell lines, and the data of Figure 1(b) indicated that miR-335-5p was notably decreased in UL cell lines especially in HCC1688 and SK-UT-1 cells relative to that in PHM1-31 cells. These data suggested that miR-335-5p might act as a tumor suppressor in UL progression.

3.2. Upregulation of miR-335-5p Inhibits Viability and Proliferation, Promotes Apoptosis, and Induces Cell Cycle Arrest at G1 Phase in UL Cell Lines. Functionally, CCK-8 assay was performed to evaluate the role of miR-335-5p in viability of UL cell lines. As indicated in Figure 2(a), overexpression of miR-335-5p significantly inhibited viability of HCC1688 and SK-UT-1 cells in a time-dependent manner compared with the NC mimic group. Besides, colony formation and EdU assays were carried out to determine the effects of miR-335-5p on proliferation of UL cell lines. As shown in Figures 2(b) and 2(c), miR-335-5p mimic remarkably decreased the proliferative potential of HCC1688 and SK-UT-1 cells relative to the NC mimic group. Moreover, western blot was used to investigate the effects of miR-335$5 \mathrm{p}$ on levels of proliferation-related proteins. As expected, upregulation of miR-335-5p reduced the protein levels of PCNA and Ki-67 compared with the NC mimic group (Figure 2(d)). Additionally, flow cytometry analysis was adopted to explore the role of miR-335-5p in cell apoptosis and cycle distribution of UL cell lines. The data of Figures 2(e) and 2(g) displayed that miR-335-5p mimic obviously promoted cell apoptosis and cell cycle arrest at G1 phase of HCC1688 and SK-UT-1 cells relative to the NC mimic group. Furthermore, western blot was also used to investigate the effects of miR-335-5p on levels of cell apoptosis- and cell cycle-related proteins. As displayed in Figures 2(f) and 2(h), upregulation of miR-335-5p reduced the protein levels of Cyclin A1, Cyclin B1, Cyclin D2, and $\mathrm{Bcl}-2$, while it increased the protein levels of p27, Bax, Cleaved caspase-3, and Cleaved caspase- 9 compared with the NC mimic group. These data suggested that upregulation of miR-335-5p inhibited viability and proliferation, promoted apoptosis, and induced cell cycle arrest at G1 phase in UL cell lines.

3.3. ARGLU1 Is a Direct Target of $m i R-335-5 p$. To explore the possible downstream targets of miR-335-5p, ENCORI and miRDB were carried out. As shown in Figure 3(a), a total of 6 targets were predicted. Among them, only ARGLU1 was negatively associated with miR-335-5p (Figure 3(b)). Moreover, dual-luciferase reporter assay was performed to further confirm the target relationship between miR-335-5p and ARGLU1. As shown in Figure 3(c), the luciferase activity of ARGLU1 $3^{\prime}$-UTR was significantly reduced when the cells were transfected with miR-335-5p mimic. However, when the putative binding sites were mutated, the miR-335-5p mimic exhibited modest effects. Moreover, to investigate the negative association between miR-335-5p and ARGLU1, qRT-PCR assay was used to detect the expression of ARGLU1 in HCC1688 and SK- 


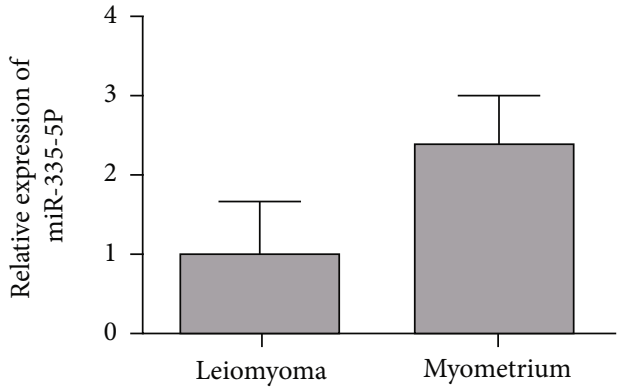

Uterine tissue

(a)

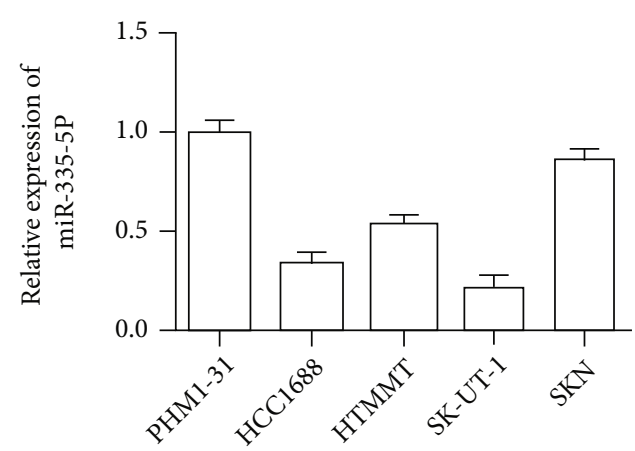

(b)

FIgURE 1: miR-335-5p is upregulated in UL tissues and cell lines. (a) The expression of miR-335-5p in UL tissues was detected by qRT-PCR assay. ${ }^{*} P<0.05 v s$. normal tissues. (b) The expression of miR-335-5p in UL cell lines was detected by qRT-PCR assay. ${ }^{* *} P<0.01 v s$. PHM131 cells. All data were presented as the mean \pm SD. $n=3$.

UT-1 cells transfected with the miR-335-5p inhibitor. The data of Figure 3(d) showed that the mRNA expression of ARGLU1 was obviously upregulated in HCC1688 and SKUT-1 cells transfected with the miR-335-5p inhibitor. Moreover, the expression of ARGLU1 in clinical UL tissues was determined by qRT-PCR assay. As expected, ARGLU1 was obviously upregulated in UL tissues compared with that in corresponding adjacent tissues (Figure 3(e)). These data suggested that ARGLU1 was a direct target of miR-335-5p and was negatively associated with miR-335-5p in UL.

\subsection{ARGLU1 Mediates the Inhibitory Effects of miR-335-5p} on the UL Cell Lines. To investigate whether miR-335-5p exhibited its functional role in progression of UL, serious rescue experiments were carried out. The results of CCK-8 assay (Figure 4(a)) showed that overexpression of ARGLU1 partially restored the inhibitory effects of miR-335-5p mimic on the viability of HCC1688 and SK-UT-1 cells. Besides, colony formation and EdU assays displayed that pc-ARGLU1 partially restored the suppressive effects of miR-335-5p mimic on the proliferation of HCC1688 and SK-UT-1 cells (Figures 4(b) and 4(c)). In addition, flow cytometry analysis showed that overexpression of ARGLU1 partially restored the effects of miR-335-5p mimic on cell apoptosis and cell cycle distribution of HCC1688 and SK-UT-1 cells (Figures 4(e) and 4(g)). Moreover, the data of Figures 4(d), 4(f), and 4(h) indicated that the upregulation of ARGLU1 partially restored the levels of proliferation, cell apoptosis, and cell cycle-related proteins of HCC1688 and SK-UT-1 cells transfected with miR-335-5p mimic. These data suggested that ARGLU1 was an important mediator to link the function of miR-335-5p for the progression of UL.

\section{Discussion}

UL, the most common benign tumor of reproductive system in women of childbearing age, significantly affects women's reproductive ability and the success rate of assisted reproductive technology [19]. Early identification and diagnosis of UL are the key to reduce infertility caused by uterine factors [20]. In recent years, a number of reports on UL and
miRNAs have emerged. During the progress of UL, many miRNAs act as oncogenes such as miR-200c, miR-139-5p, and miR-197 [14, 21, 22], and many miRNAs function as tumor suppressors like miR-15b, miR-93, and miR-106b $[13,23,24]$. Similarly, in our present study, miR-335-5p was obviously downregulated in clinical UL tissues and cell lines, which was highly consistent with previous studies. miR-335-5p is significantly downregulated in colorectal cancer, thyroid cancer, and NSCLC [25-27]. These findings suggested that miR-335-5p might act as a tumor suppressor in UL.

miRNAs participate in gene regulation and many biological processes, which is the main phenomenon of epigenetics [28]. However, the molecular mechanisms of miRNAs regulating the function of UL cells are still unclear. For example, downregulation of miR-197 increases cell growth and induces cell cycle arrest in the G0/G1 phase in vitro of UL cells, while upregulation of miR-197 expression has the opposite effects [29]. In addition, overexpression of miR-93 reduces the cell viability, promotes cell cycle arrest and apoptosis, and inhibits migration of UL cells [13]. miR-335-5p, functioning as a tumor suppressor, has been reported to exhibit vital role in the development of many tumors. For instance, upregulation of miR-335-5p suppresses proliferation and induces cell cycle arrest of NSCLC cells [30]. In addition, overexpression of miR-335-5p inhibits cell proliferation and suppresses migration ability and invasion of colorectal cancer cells, while the knockdown of miR-335$5 \mathrm{p}$ shows the opposite results [31]. Moreover, upregulation of miR-335-5p inhibits proliferation, migration, and invasion and induces apoptosis of thyroid cancer cells [16]. Cellular behavioral experiments revealed that miR-335-5p mimics and Rho-associated coiled-coil containing protein kinase 1 (ROCK1) knockdown reversed the effects of upregulated differentiation antagonizing nonprotein coding RNA (DANCR) on proliferation, migration, invasion, and epithelial-mesenchymal transition (EMT) of cervical cancer cells by rescue assays. This study demonstrated that DANCR promoted cervical cancer progression by functioning as a competing endogenous RNA (ceRNA) to regulate ROCK1 expression via sponging miR-335-5p, suggesting a novel 

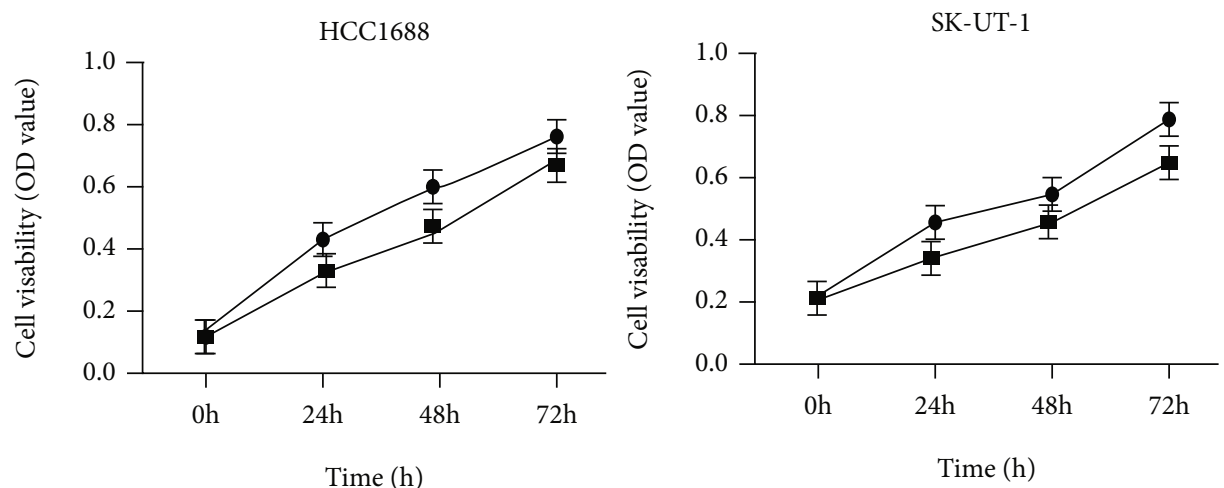

$\rightarrow$ NC mimic

$\rightarrow$ miR-335-5P mimic

(a)
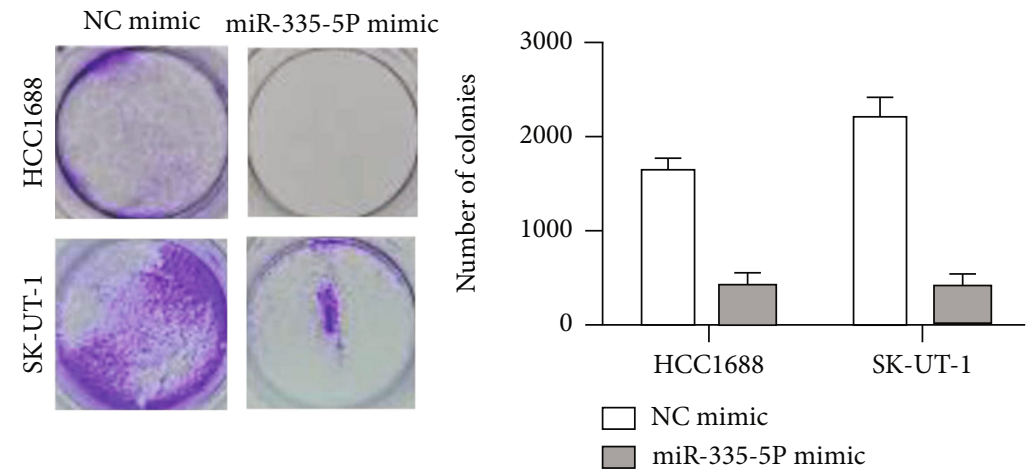

(b)

Figure 2: Continued. 

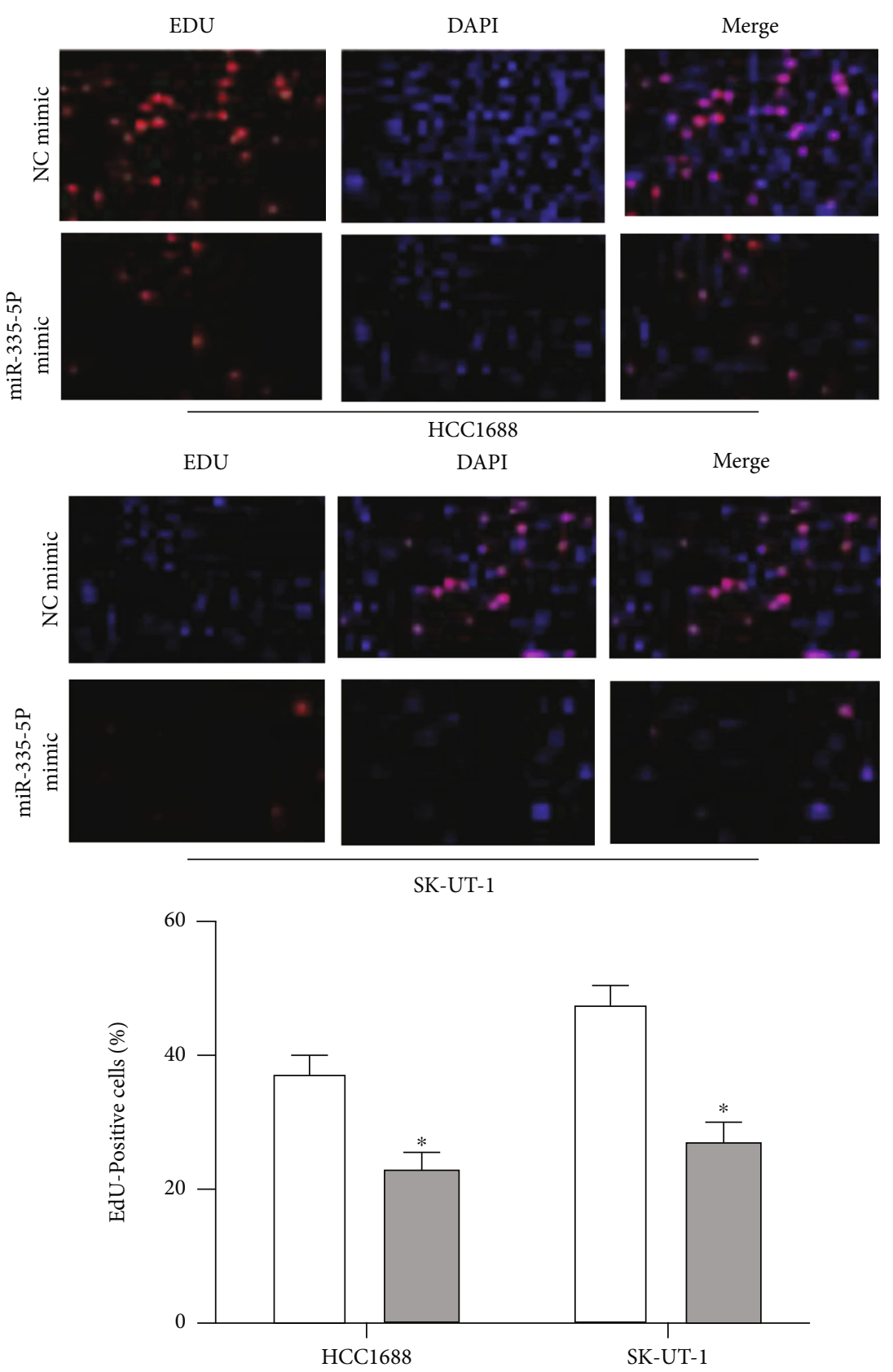

$\square$ NC mimic

$\square$ miR-335-5P mimic

(c)
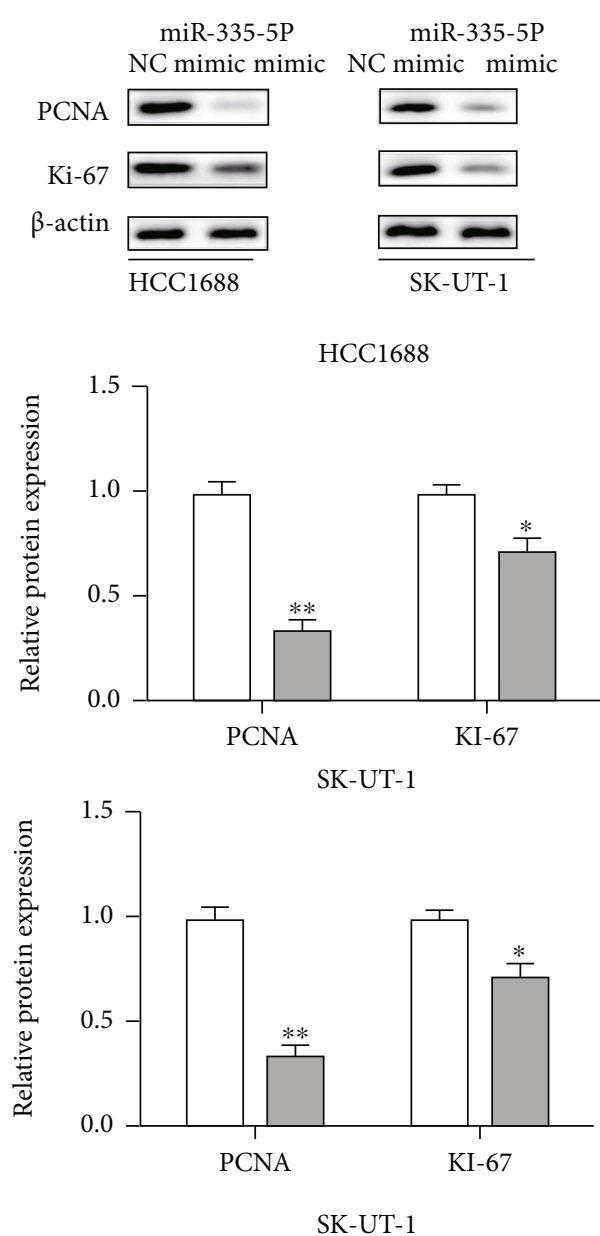

$\square$ NC mimic

$\square$ miR-335-5P mimic

(d)

FIgUre 2: Continued. 

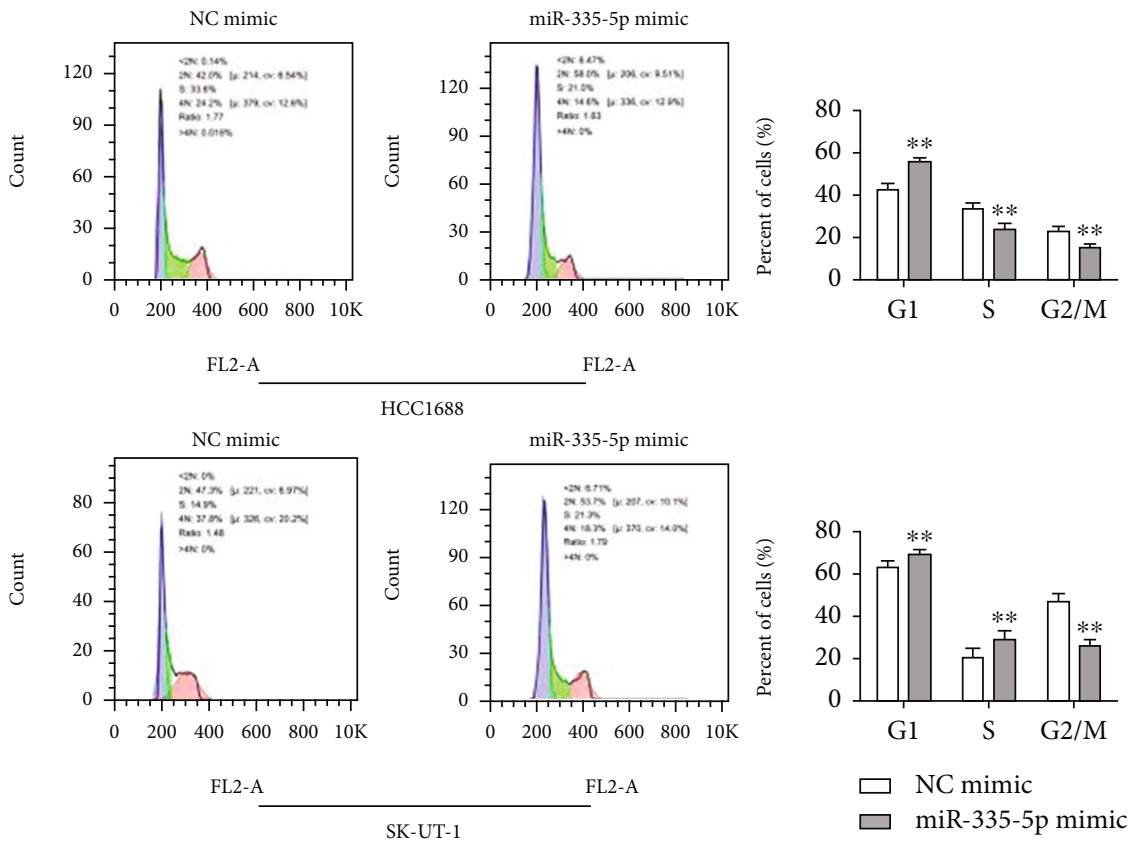

(e)
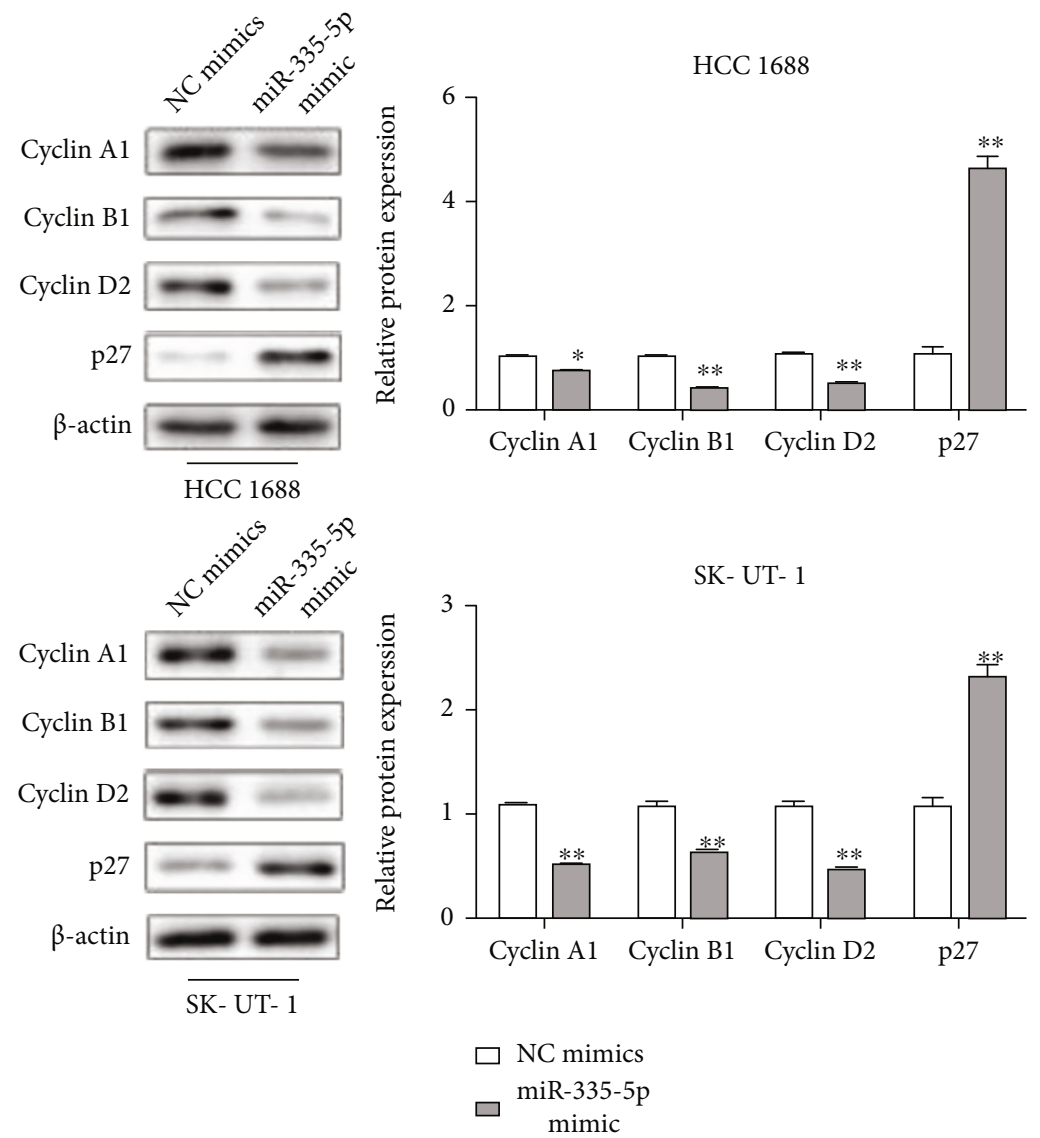

(f)

FIgURe 2: Continued. 

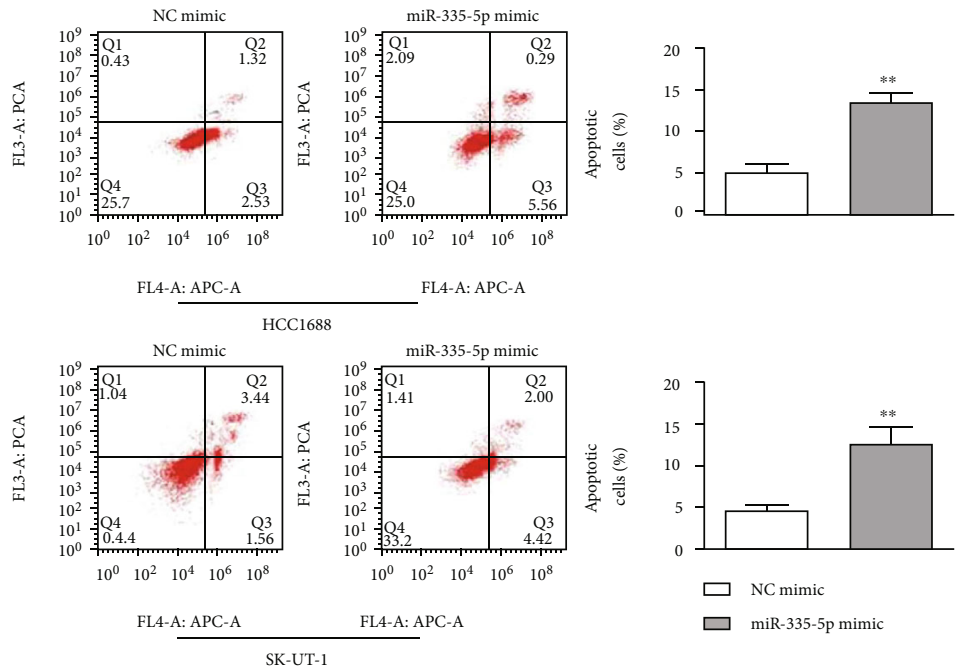

(g)
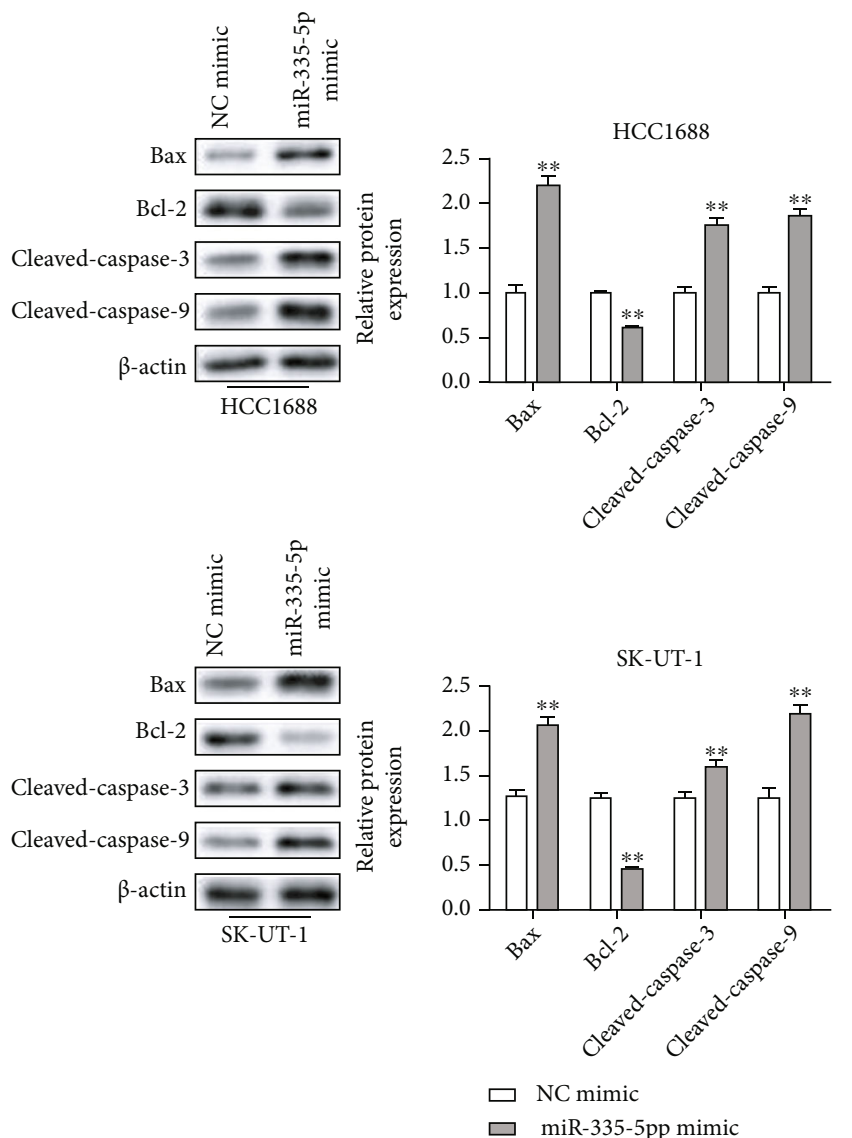

(h)

FIGURE 2: Upregulation of miR-335-5p inhibits viability and proliferation, promotes apoptosis, and induces cell cycle arrest at G1 phase in UL cell lines. (a) The viability of HCC1688 and SK-UT-1 cells transfected with miR-335-5p mimic was assessed by CCK-8 assay at indicated times. The proliferation of HCC1688 and SK-UT-1 cells transfected with miR-335-5p mimic was assessed by (b) colony formation and (c) EdU assays. (d) The expression levels of proliferation-related proteins, including PCNA and Ki-67, were evaluated by western blot assay. (e) The cell cycle distribution of HCC1688 and SK-UT-1 cells transfected with miR-335-5p mimic was assessed by flow cytometry analysis assay. (f) The expression levels of cell cycle-related proteins, including Cyclin A1, Cyclin B1, Cyclin D2, and p27, were evaluated by western blot assay. (g) The cell apoptosis of HCC1688 and SK-UT-1 cells transfected with miR-335-5p mimic was assessed by flow cytometry analysis assay. (h) The expression levels of cell apoptosis-related proteins, including Bcl-2, Bax, Cleaved caspase-3, and Cleaved caspase-9, were evaluated by western blot assay. ${ }^{*} P<0.05$ and $^{* *} P<0.01 v s$. the NC mimic group. All data were presented as the mean \pm SD. $n=3$. 

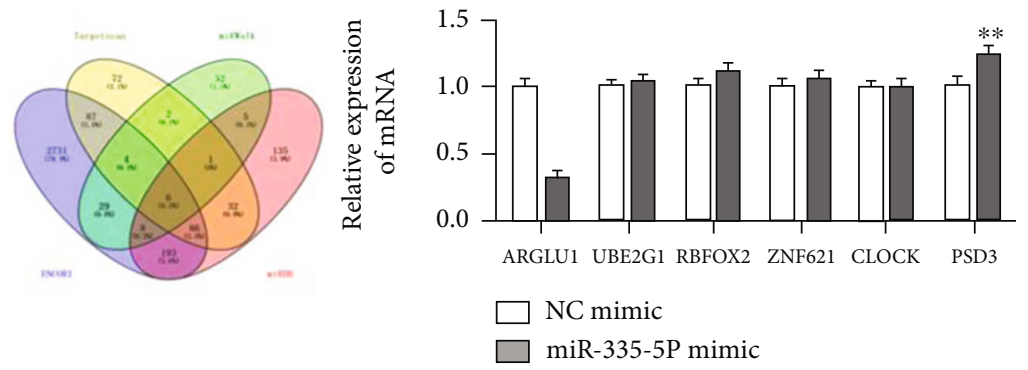

(a)

\begin{tabular}{|c|c|}
\hline ARGLU1 WT & $5^{\prime}$-ccuugugauacUGUUGCUCUUGa- $3^{\prime}$ \\
\hline Hsa-miR-335-5P & $\begin{array}{c}|:||||||||||||| c|c| \\
3^{\prime} \text {-uguaaaagcaAUAACGAGAACu-5 }\end{array}$ \\
\hline ARGLU1 Mut & $5^{\prime}$-ccuugugauacAUAACGAGAACa-3' \\
\hline
\end{tabular}

(b)
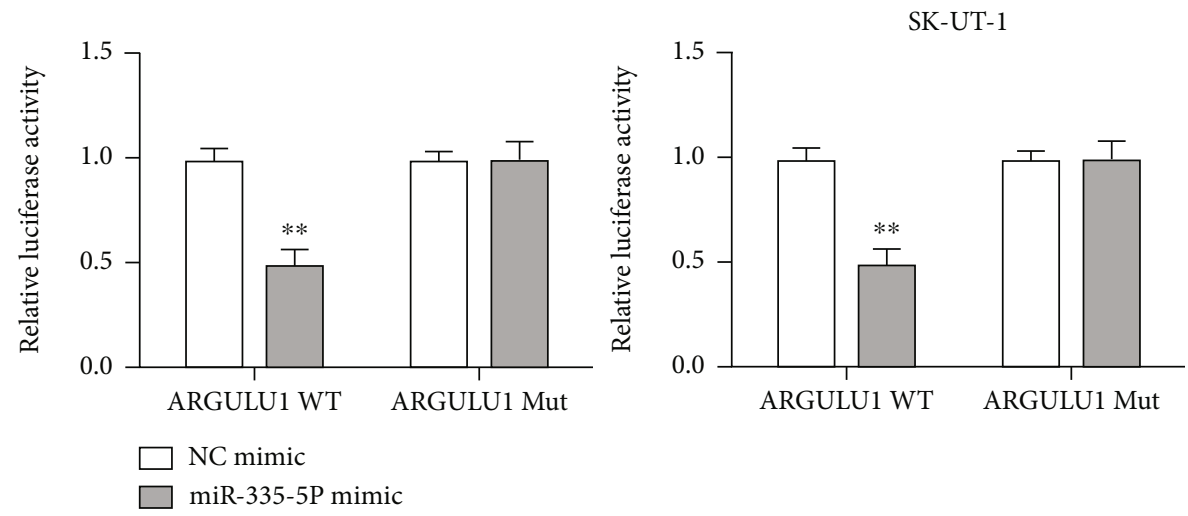

(c)

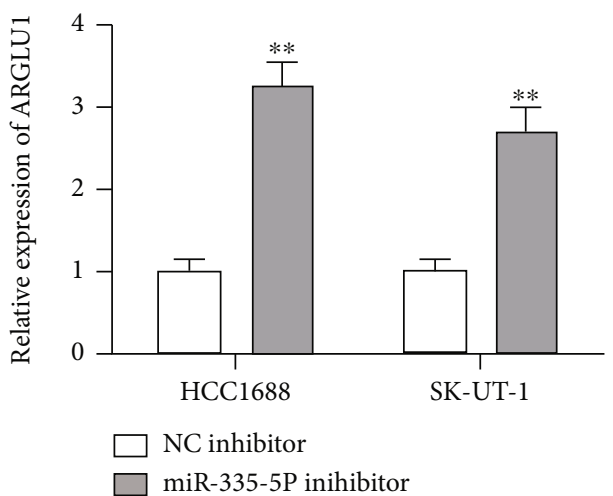

(d)

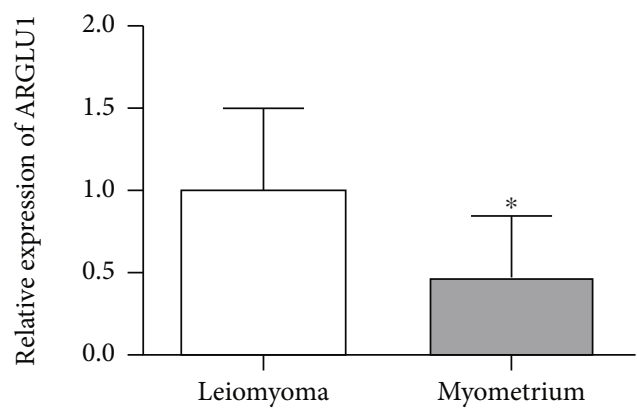

(e)

FIgURe 3: ARGLU1 is direct target of miR-335-5p. (a) The candidate targets regulated by miR-335-5p were predicted by NCORI and miRDB. (b) The binding sites between miR-335-5p and ARGLU1. (c) Dual-luciferase reporter analysis was employed to validate the coactions between miR-335-5p and ARGLU1. ${ }^{* *} P<0.01 \mathrm{vs}$. the NC mimic group. (d) qRT-PCR assay was used to evaluate the mRNA expression of ARGLU1 in HCC1688 and SK-UT-1 cells transfected with miR-335-5p inhibitor. ${ }^{* *} P<0.01 v s$. NC inhibitor. (e) The expression of ARGLU1in UL tissues was detected by qRT-PCR assay. ${ }^{*} P<0.05$ s. normal tissues. All data were presented as the mean \pm SD. $n=3$.

potential therapeutic target for cervical cancer $[16,17]$. Similarly, in our present study, overexpression of miR-335-5p notably inhibited viability and proliferation and induced cell apoptosis and cell cycle arrest of UL cells. These results were similar to the previous findings.
The activation of protooncogenes or the inactivation of tumor suppressor genes, the key link in the process of tumor occurrence and development, can cause tumorigenesis of cells due to uncontrolled growth $[32,33]$. In organism, miRNA regulates the biological behavior of cells by 

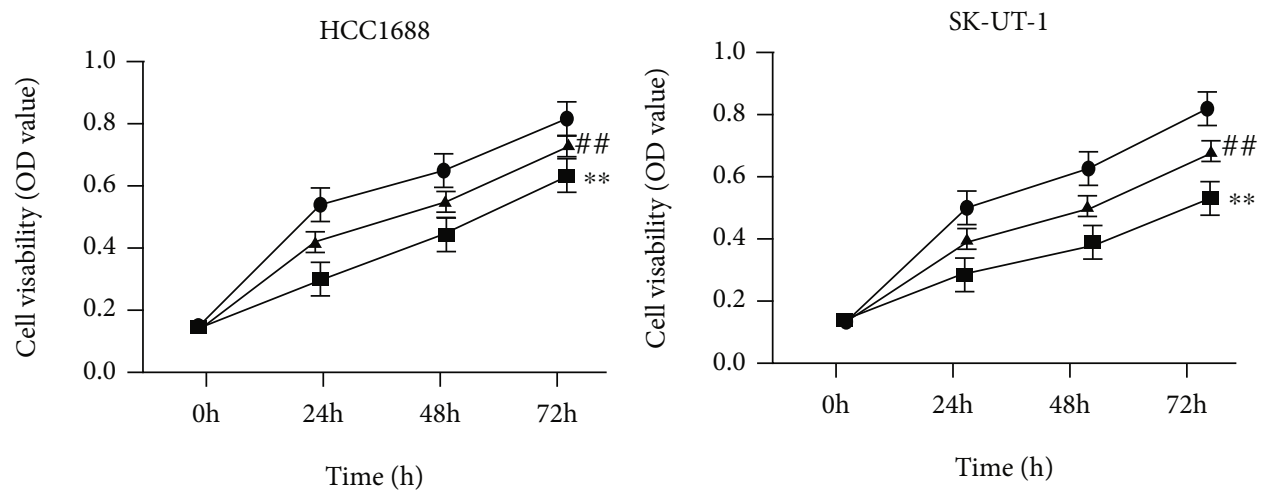

- $\mathrm{NC}$ mimic+pc-NC

- miR-335-5P mimic +Pc-NC

— miR-335-5P mimic+Pc-ARGLU1

(a)

miR-335-5P miR-335-5P mimic

$\mathrm{NC}$ mimictpc-NC mimic+Pc-NC +Pc-ARGLU1
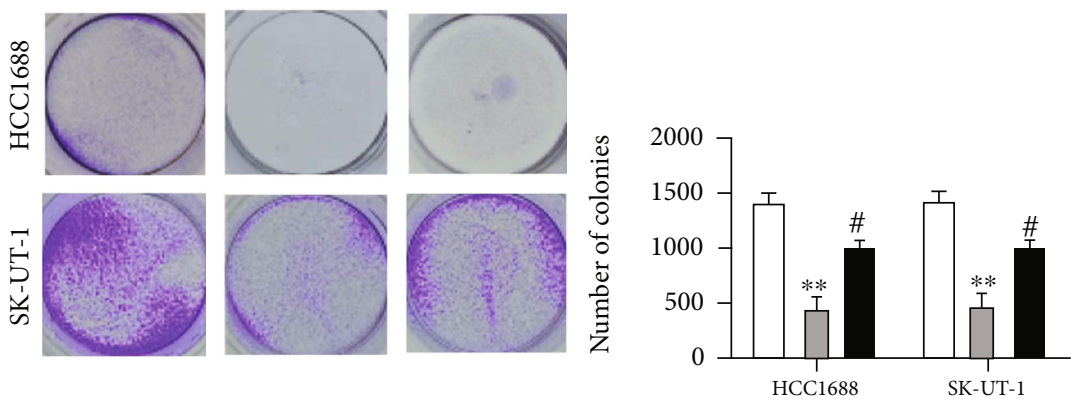

$\square \mathrm{NC}$ mimic+pc-NC

$\square$ miR-335-5P mimic+Pc-NC

- miR-335-5P mimic+Pc-ARGLU1

(b)

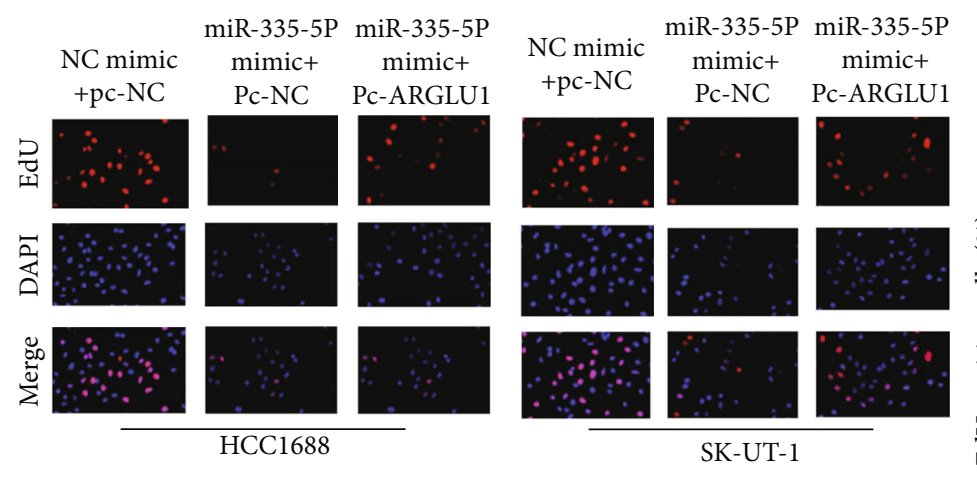

(c)

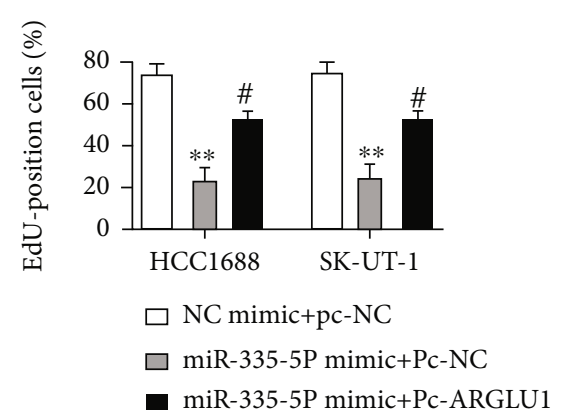

FIgURe 4: Continued. 

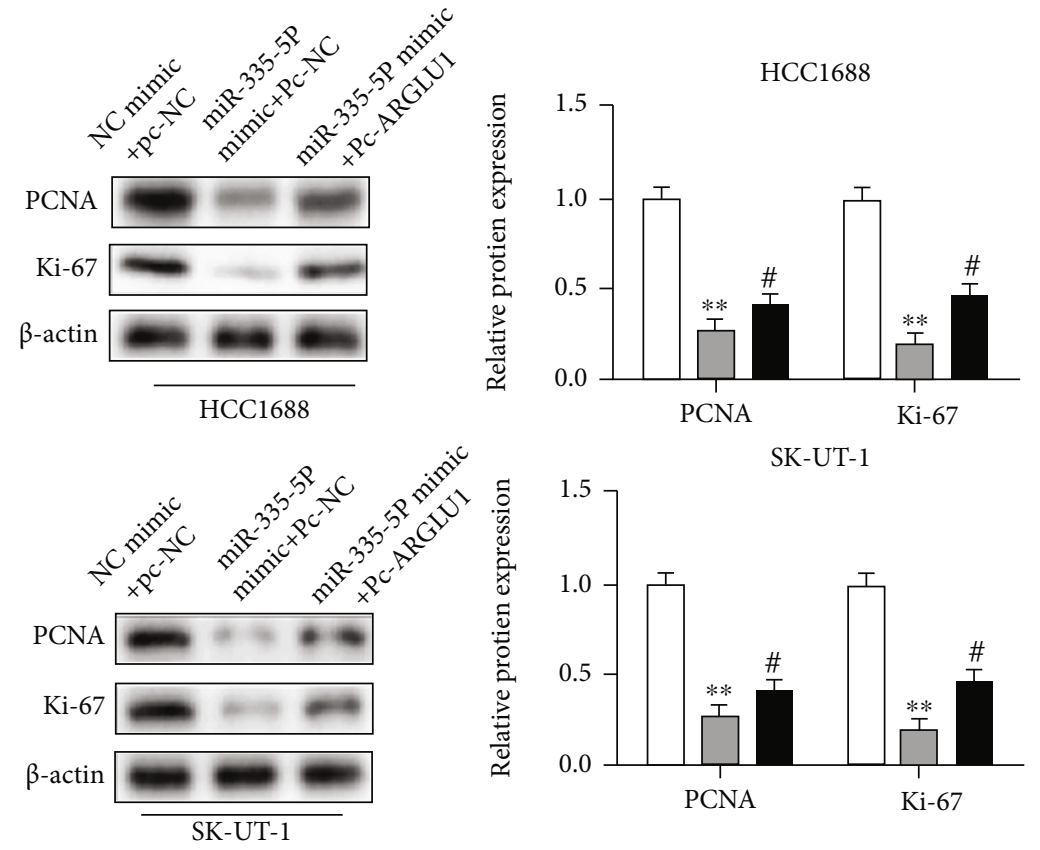

(d)
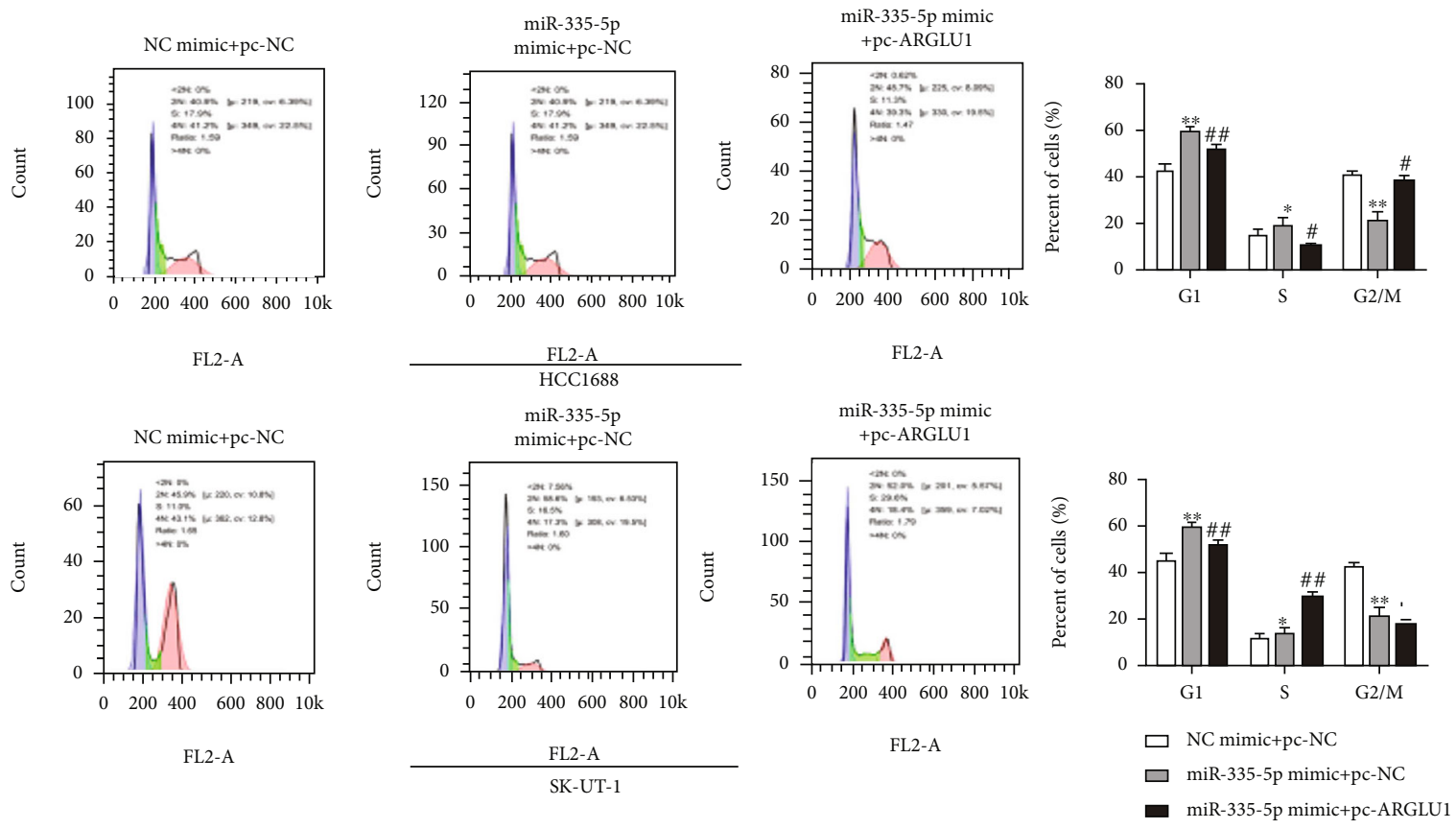

(e)

FIgure 4: Continued. 


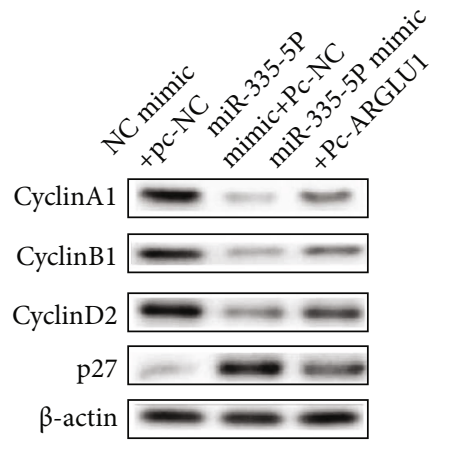

HCC1688
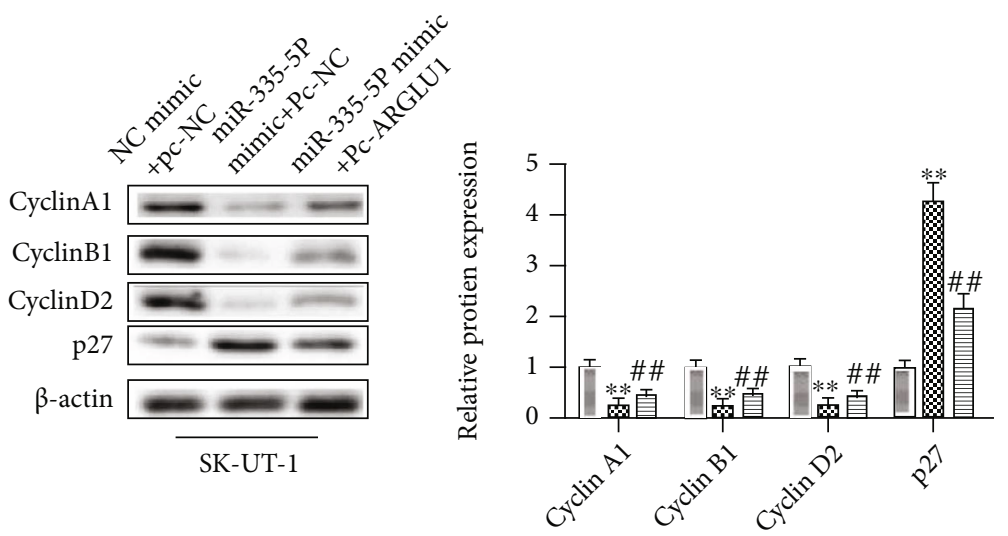

$\square$ NC mimic + pc-NC

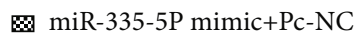

目 miR-335-5P mimic+Pc-ARGLU1

(f)
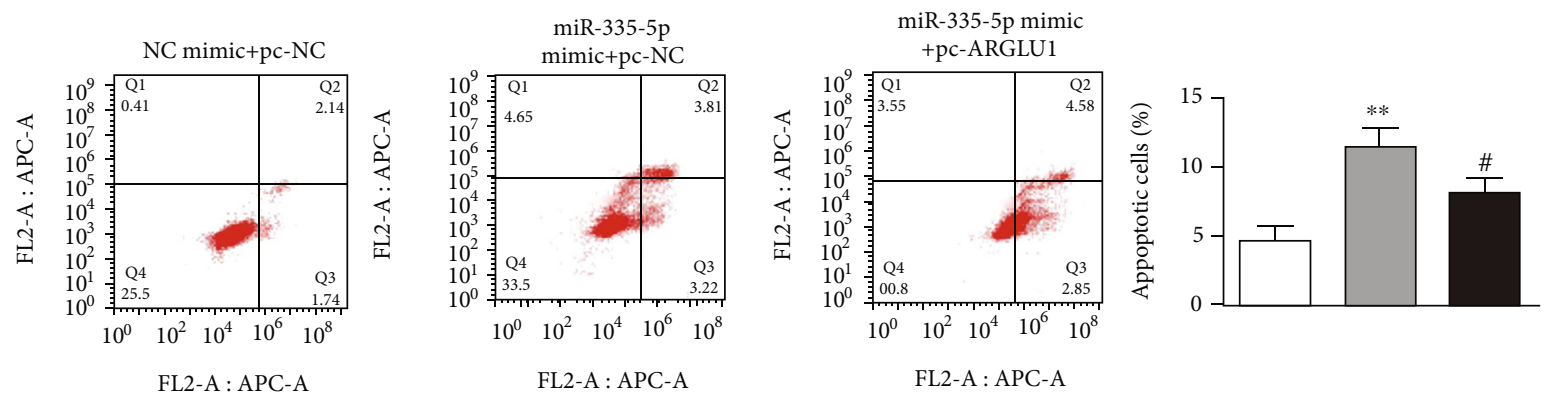

HCC 1688
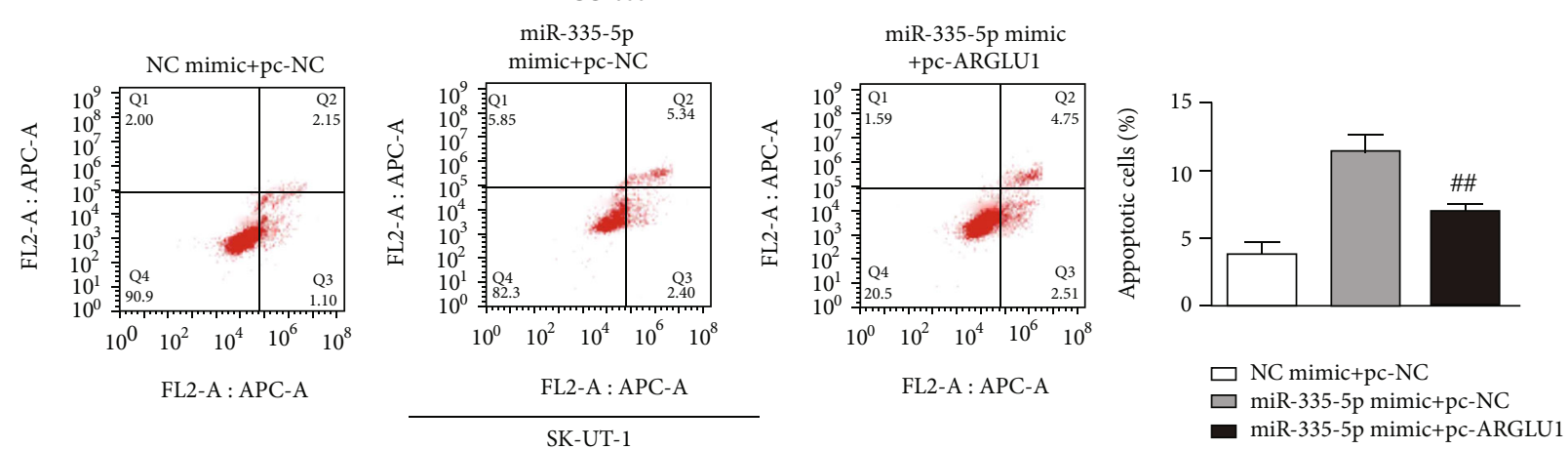

(g)

Figure 4: Continued. 


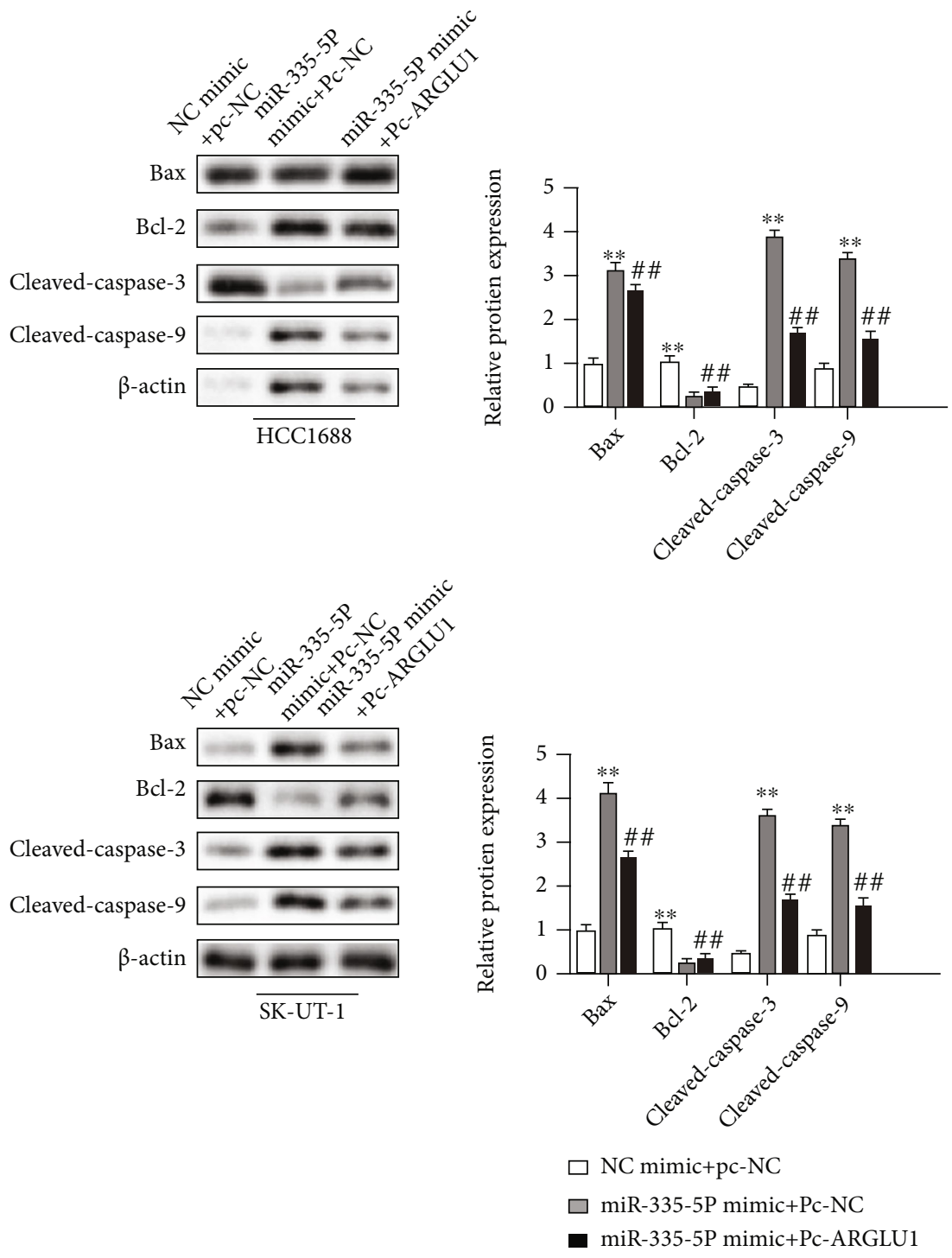

(h)

FIGURE 4: ARGLU1 mediates the inhibitory effects of miR-335-5p on the UL cell lines. (a) The viability of HCC1688 and SK-UT-1 cells transfected with miR-335-5p mimic or cotransfected with miR-335-5p mimic and pc-ARGLU1 was assessed by CCK-8 assay at indicated times. The proliferation of HCC1688 and SK-UT-1 cells transfected with miR-335-5p mimic or cotransfected with miR-335-5p mimic and pc-ARGLU1 was assessed by (b) colony formation and (c) EdU assays. (d) The expression levels of proliferation-related proteins, including PCNA and Ki-67, were evaluated by western blot assay. (e) The cell cycle distribution of HCC1688 and SK-UT-1 cells transfected with miR-335-5p mimic or cotransfected with miR-335-5p mimic and pc-ARGLU1 was assessed by flow cytometry analysis assay. (f) The expression levels of cell cycle-related proteins, including Cyclin A1, Cyclin B1, Cyclin D2, and p27, were evaluated by western blot assay. (g) The cell apoptosis of HCC1688 and SK-UT-1 cells transfected with miR-335-5p mimic or cotransfected with miR335-5p mimic and pc-ARGLU1 was assessed by flow cytometry analysis assay. (h) The expression levels of cell apoptosis-related proteins, including Bcl-2, Bax, Cleaved caspase-3, and Cleaved caspase- 9 , were evaluated by western blot assay. ${ }^{* *} P<0.01$ vs. the NC mimic +pc-NC group. ${ }^{\#} P<0.05$ and ${ }^{\# \#} P<0.01 v s$. the miR-335-5p mimic + pc-NC group. All data were presented as the mean \pm SD. $n=3$.

regulating the expression of corresponding target mRNAs. For example, miR-197 is lowly expressed in UL tissues. Downregulation of miR-197 promotes cell growth and induces cell cycle arrest in the G0/G1 phase by directly targeting IGFBP5 [34]. Besides, miR-139-5p is lowly expressed in UL tissues, and upregulation of miR-139-5p inhibits the growth of UL cells and induces apoptosis and G1 phase arrest through negatively regulating TPD52 [14]. To further explore the biological mechanisms of miRNAs, we need to find and confirm its target mRNAs in a specific biological process. In this study, ENCORI and miRDB were performed to predict the candidate target mRNAs of miR-335-5p, and ARGLU1 was selected as a candidate target of miR-335-5p. Further, dual-luciferase reporter gene assay system was adopted to confirm that ARGLU1 was a direct target of miR-335-5p. ARGLU1 is a highly polarized protein enriched 
in positively charged amino acids at the first $98 \mathrm{~N}$-terminal amino acids (27 arginine and 8 lysine, or 36\%) with the rest of the sequence highly enriched for negatively charged residues (49 glutamate, or 28\%) [35]. Previous studies have shown that ectopic expression of ARGLU1 is closely related to the occurrence and development of many tumors. For example, ARGLU1 is overexpressed in breast cancer, thus notably inhibiting the progression of breast cancer [36]. Therefore, in our study, we found that ARGLU1 was highly expressed in UL tissues and cell lines and upregulation of ARGLU1 significantly restored the effects of miR-335-5p mimic on viability, proliferation, apoptosis, and cell cycle distribution of UL cells. However, the specific mechanism of miR-335-5p on the regulating the development of UL remains elusive. More researches in vivo should be conducted to validate our conclusions.

In summary, our findings revealed that miR-335-5p was significantly downregulated in UL tissues and cell lines. Upregulation of miR-335-5p significantly inhibited viability and proliferation, promoted apoptosis, and induced cell cycle arrest of UL cells via targeting ARGLU1, indicating that miR-335-5p might emerge as an effective target for treating UL patients.

\section{Data Availability}

The authors confirm that the data supporting the findings of this study are available within the article.

\section{Conflicts of Interest}

The authors declare that the research was conducted in the absence of any commercial or financial relationships that could be construed as a potential conflict of interest.

\section{Authors' Contributions}

Sumei Fan and Yan Sun conceived and designed the study. Wei Zhao, Yingyan Zhao, and Ling Chen performed the literature search, data collection, and analysis. Wei Zhao and Yingyan Zhao drafted the manuscript. Sumei Fan and Yan Sun confirmed the authenticity of all the raw data. Wei Zhao and Sumei Fan provided funding support. All authors read and approved the final manuscript. Wei Zhao, Yingyan Zhao, and Ling Chen contributed equally to this work.

\section{References}

[1] T. D. Lewis, M. Malik, J. Britten, A. M. San Pablo, and W. H. Catherino, "A comprehensive review of the pharmacologic management of uterine leiomyoma," BioMed Research International, vol. 2018, Article ID 2414609, 11 pages, 2018.

[2] J. A. Gingold, A. Chichura, M. P. Harnegie, and R. M. Kho, "Perioperative interventions to minimize blood loss at the time of hysterectomy for uterine leiomyomas: a systematic review and meta-analysis," Journal of Minimally Invasive Gynecology, vol. 26, no. 7, pp. 1234-1252.e1, 2019.

[3] E. Csatlós, J. Rigó Jr., M. Laky, and J. G. Joó, “Gene expression patterns of insulin-like growth factor 2 in human uterine fibroid tissues: a genetic study with clinical correlations,"
Gynecologic and Obstetric Investigation, vol. 75, no. 3, pp. 185-190, 2013.

[4] G. P. Flake, J. Andersen, and D. Dixon, "Etiology and pathogenesis of uterine leiomyomas: a review," Environmental Health Perspectives, vol. 111, no. 8, pp. 1037-1054, 2003.

[5] X. Xu, J. J. Kim, Y. Li, J. Xie, C. Shao, and J. J. Wei, “Oxidative stress-induced miRNAs modulate AKT signaling and promote cellular senescence in uterine leiomyoma," Journal of Molecular Medicine, vol. 96, no. 10, pp. 1095-1106, 2018.

[6] B. Georgieva, I. Milev, I. Minkov, I. Dimitrova, A. P. Bradford, and V. Baev, "Characterization of the uterine leiomyoma microRNAome by deep sequencing," Genomics, vol. 99, no. 5, pp. 275-281, 2012.

[7] Y. J. Kim, Y. Kim, J. Shin, H. Kim, S. Y. Ku, and C. Suh, "Variation in microRNA expression profile of uterine leiomyoma with endometrial cavity distortion and endometrial cavity non-distortion," International Journal of Molecular Sciences, vol. 19, no. 9, p. 2524, 2018.

[8] T. D. Chuang and O. Khorram, "Regulation of cell cycle regulatory proteins by microRNAs in uterine leiomyoma," Reproductive Sciences, vol. 26, no. 2, pp. 250-258, 2019.

[9] R. Lazzarini, M. Caffarini, G. Delli Carpini, A. Ciavattini, R. di Primio, and M. Orciani, "From 2646 to 15: differentially regulated microRNAs between progenitors from normal myometrium and leiomyoma," American Journal of Obstetrics and Gynecology, vol. 222, no. 6, pp. 596.e1-596.e9, 2020.

[10] B. Liu, J. Li, and M. J. Cairns, "Identifying miRNAs, targets and functions," Briefings in Bioinformatics, vol. 15, no. 1, pp. 1-19, 2014.

[11] M. Tafrihi and E. Hasheminasab, "MiRNAs: biology, biogenesis, their web-based tools, and databases," Microrna, vol. 8, p. 4, 2019.

[12] S. P. Kabekkodu, V. Shukla, V. K. Varghese, J. D' Souza, S. Chakrabarty, and K. Satyamoorthy, "Clustered miRNAs and their role in biological functions and diseases," Biological Reviews of the Cambridge Philosophical Society, vol. 93, no. 4, pp. 1955-1986, 2018.

[13] D. Zhang, E. Liu, W. Tian, Z. Zhang, L. Wang, and J. Li, "RETRACTED:MiR-93 blocks cell cycle progression and promotes apoptosis in uterine leiomyoma cells by targeting CCND1," The Anatomical Record, vol. 303, no. 9, pp. 23722381, 2020.

[14] H. Chen, H. Xu, Y. Meng, Y. Zhang, J. Chen, and X. Wei, "miR-139-5p regulates proliferation, apoptosis, and cell cycle of uterine leiomyoma cells by targeting TPD52," Oncotargets and Therapy, vol. Volume 9, pp. 6151-6160, 2016.

[15] D. M. Jiao, L. Yan, L. S. Wang et al., "Exploration of inhibitory mechanisms of curcumin in lung cancer metastasis using a miRNA- transcription factor-target gene network," PLoS One, vol. 12, no. 2, article e0172470, 2017.

[16] L. Luo, L. Xia, B. Zha et al., "miR-335-5p targeting ICAM-1 inhibits invasion and metastasis of thyroid cancer cells," Biomedicine \& Pharmacotherapy, vol. 106, pp. 983-990, 2018.

[17] Y. An, H. Cai, Y. Zhang et al., "circZMYM2 competed endogenously with miR-335-5p to regulate JMJD2C in pancreatic cancer," Cellular Physiology and Biochemistry, vol. 51, no. 5, pp. 2224-2236, 2018.

[18] W. du, H. Tang, Z. Lei et al., "miR-335-5p inhibits TGF- $\beta 1$ induced epithelial-mesenchymal transition in non-small cell lung cancer via ROCK1," Respiratory Research, vol. 20, no. 1, p. $019,2019$. 
[19] J. K. Schoolmeester and L. A. Erickson, "Uterine leiomyoma," Mayo Clinic Proceedings, vol. 94, no. 10, pp. 2150-2151, 2019.

[20] S. Sato, R. Maekawa, Y. Yamagata et al., "Identification of uterine leiomyoma-specific marker genes based on DNA methylation and their clinical application," Scientific Reports, vol. 6, no. 1, p. 30652, 2016.

[21] T. D. Chuang and O. Khorram, “miR-200c regulates IL8 expression by targeting IKBKB: a potential mediator of inflammation in leiomyoma pathogenesis," PLoS One, vol. 9, no. 4, article e95370, 2014.

[22] J. Ling, X. Wu, Z. Fu, J. Tan, and Q. Xu, "Systematic analysis of gene expression pattern in has-miR-197 over-expressed human uterine leiomyoma cells," Biomedicine \& Pharmacotherapy, vol. 75, pp. 226-233, 2015.

[23] Y. Guan, L. Guo, L. Zukerberg, B. R. Rueda, and A. K. Styer, "MicroRNA-15b regulates reversion-inducing cysteine-rich protein with Kazal motifs (RECK) expression in human uterine leiomyoma," Reproductive Biology and Endocrinology, vol. 14, no. 1, p. 016, 2016.

[24] T. D. Chuang, X. Luo, H. Panda, and N. Chegini, "miR-93/ 106b and their host gene, MCM7, are differentially expressed in leiomyomas and functionally target F3 and IL-8," Molecular Endocrinology, vol. 26, no. 6, pp. 1028-1042, 2012.

[25] Q. Jia, L. Ye, S. Xu et al., "Circular RNA 0007255 regulates the progression of breast cancer through miR-335-5p/SIX2 axis," Thorac Cancer, vol. 11, no. 3, pp. 619-630, 2020.

[26] J. Zou, K. Wu, C. Lin, and Z. G. Jie, "LINC00319 acts as amicroRNA-335-5psponge to accelerate tumor growth and metastasis in gastric cancer by upregulatingADCY3," American Journal of Physiology. Gastrointestinal and Liver Physiology, vol. 318, no. 1, pp. G10-G22, 2020.

[27] I. Tinay, M. Tan, B. Gui, L. Werner, A. S. Kibel, and L. Jia, "Functional roles and potential clinical application of miRNA-345-5p in prostate cancer," Prostate, vol. 78, no. 12, pp. 927-937, 2018.

[28] M. Acunzo, G. Romano, D. Wernicke, and C. M. Croce, "MicroRNA and cancer - a brief overview," Advances in Biological Regulation, vol. 57, pp. 1-9, 2015.

[29] X. Wu, J. Ling, Z. Fu, C. Ji, J. Wu, and Q. Xu, "Effects of miRNA-197 overexpression on proliferation, apoptosis and migration in levonorgestrel treated uterine leiomyoma cells," Biomedicine \& Pharmacotherapy, vol. 71, pp. 1-6, 2015.

[30] H. Tang, W. du, Y. Jiang, H. Li, H. Bo, and S. Song, "Upregulated expression of ROCK1 promotes cell proliferation by functioning as a target of miR-335-5p in non-small cell lung cancer," Journal of Cellular Physiology, vol. 29, article 28886, 2019.

[31] L. Wang, Y. Zhao, M. Xu, F. Zhou, and J. Yan, "Serum miR1301-3p, miR-335-5p, miR-28-5p, and their target B7-H3 may serve as novel biomarkers for colorectal cancer," Journal of BUON, vol. 24, p. 1120, 2019.

[32] J. H. Lee, Y. S. Choi, J. H. Park et al., “MiR-150-5p may contribute to pathogenesis of human leiomyoma via regulation of the Akt/p27Kip1 pathway in vitro," International Journal of Molecular Sciences, vol. 20, no. 11, p. 2684, 2019.

[33] J. L. Lu, L. Zhao, S. C. Han et al., "MiR-129 is involved in the occurrence of uterine fibroid through inhibiting TET1," European Review for Medical and Pharmacological Sciences, vol. 22, p. 4419, 2018.
[34] J. Ling, L. Jiang, C. Zhang, J. Dai, Q. Wu, and J. Tan, "Upregulation of miR-197 inhibits cell proliferation by directly targeting IGFBP5 in human uterine leiomyoma cells," In Vitro Cellular \& Developmental Biology. Animal, vol. 51, no. 8, pp. 835-842, 2015.

[35] L. Magomedova, J. Tiefenbach, E. Zilberman et al., "ARGLU1 is a transcriptional coactivator and splicing regulator important for stress hormone signaling and development," Nucleic Acids Research, vol. 47, no. 6, pp. 2856-2870, 2019.

[36] D. Zhang, P. Jiang, Q. Xu, and X. Zhang, “Arginine and glutamate-rich 1 (ARGLU1) interacts with mediator subunit 1 (MED1) and is required for estrogen receptor-mediated gene transcription and breast cancer cell growth," The Journal of Biological Chemistry, vol. 286, no. 20, pp. 17746-17754, 2011. 